From person to father: A grounded theory of male gender identity formation

Quinain, Khael T

Department of Psychology, University of San Carlos, Philippines (khaelquinain@gmail.com)

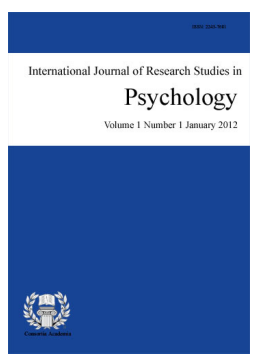

ISSN: 2243-7681

Received: 28 October 2015

Revised: 5 November 2015 DOI: $10.5861 /$ ijrsp.2015.1356
Accepted: 22 November 2015 Online ISSN: 2243-769X

OPEN ACCESS

\title{
Abstract
}

This study is a qualitative study on the formation of male gender identity. Using Grounded Theory (Charmaz, 2008), the study was able to examine how men view themselves and trace how their identities as males has come to being. It was found from the accounts of the participants that men have two identities: Identity as a Person and Identity as a Father. As a person the identities of men are focused on their personal views and desires. And as a father, their identities are built around their family and children. Further, the study was also able to identify Factors that had an impact on the formation of their identities. Male identity therefore changes across time and experience.

Keywords: masculinity; Filipino masculinity; gender; gender identity; grounded theory 


\section{From person to father: A grounded theory of male gender identity formation}

\section{Introduction}

In recent times, studies on gender identity have been gradually on the rise. However, in the last 30 years, there have been few studies of heterosexual male identity development (Frankel, 2004). This could be due to the misconception that males generally have a more "normal" experience than that of females and other groups. As Hoffman (2004) stated, models of identity development specifically intended for majority groups are considerably less prominent in literature than are models developed for non-dominant groups. Males might be viewed as the standard upon which other gender groups should be compared to. This view is problematic as it places the significance of understanding men away from the limelight of research. Nevertheless, this study attempts to outline the process of how male gender identity is developed.

\subsection{Gender Identity Development}

Attempts to explain the development of gender identity has been dominated by social-cognitive theories (e.g. Bussey \& Bandura, 2004). These theories have proposed that one's gender identity is learned through one's interactions with the environment (Bandura, 1986; Bussey \& Bandura, 2004; Deaux \& Major, 1987). Through interacting with others, an individual gathers information about what it means to be male or female. Gender identity is therefore developed over time through socialization. However, it is worth noting that while socialization is a universal process, people do not necessarily experience the same events. That is, people are exposed to different events depending on time, place, and culture. As Donahue, Robins, Roberts, and John (1993) mentioned, individuals who have experienced a variety of events might have more diverse information about themselves. This information may change a man's understanding of his identity. Also, men and women are socialized differently. As Rheingold and Cook (1975) stated, the environment is highly gendered. The environment in which one grows is organized in such a way that it promotes the traditional views related to one's gender.

Although these theories are able to adequately explain how gender identity develops, they do not identify specific factors or experiences that would influence gender identity formation. Understanding context is therefore essential to understand gender identity formation.

\subsection{Male Gender Identity in the Philippines}

The Philippines has been regarded as a patriarchal society, wherein society is organized in such a way that men are somewhat in a more advantageous position than women (Rodriguez, 1990). Furthermore, patriarchy is said to be deeply ingrained in the consciousness of Filipinos due to patriarchy as being demonstrated in family, religion, school, media, and sciences (Rodriguez, 1990). Because of this, different expectations are placed on males and females.

A dominant theme in Filipino literature is that males are expected to be the ama $n g$ tahanan (father of the home) (Jimenez, 1983), where men are expected to be the economic providers for their family. To add, Aguiling-Dalisay et al. (2000) identified two different images of the Filipino male: protector and dominator. The protector role is related to being the provider of the family, as well as being concerned about the safety and welfare of the household. On the other hand, being the dominator entails that men serve as the padre de pamilya (father of the family) and haligi ng tahanan (cornerstone of the home). This means that males are highly involved in the decision making process of the family and that they play a major role in familial concerns. Recently, Rubio and Green (2011) identified descriptive and prescriptive components of Filipino masculinity. They revealed seven emic constructs of Filipino masculinity: Sense of responsibility, Family orientedness, 
Respectful deference to spouse, women, and elders, Integrity, Intellectual pursuits, Strength, and Sense of community.

Despite these findings, it is acknowledged that Filipino masculinity could be broken down into specific masculinities. Aguiling-Dalisay, G., Nepomuceno-Van Heugten, M. L., \& Sto. Domingo, M. (1995) found out that there are differences in views of masculinity among men of different cultural groups. It was observed that masculinity was highly influenced by the values of their respective groups. For example, Religion and Tribal beliefs shaped how men view themselves. Filipino masculinity is a reflection of how Filipino society views masculinity. How a man view himself is a result of his interaction with the people and events surrounding him. Thus, male identity could be unique and the process that guides its formation could also be distinct.

This study was informed by existing literature on gender identity development and Filipino male identity. Considering the development in the field, the study wishes to further our current understanding of male identity by looking into both the process of its formation as well as how men currently view themselves.

\section{Method}

This study on male gender identity was approached from a constructivist perspective using grounded theory (Charmaz, 2008). Grounded theory conducted from a constructivist epistemology allows the researcher to be more flexible in data analysis as well as to be more receptive of the participant's views.

\subsection{Participants}

The participants of the study were 17 men. They were gathered via purposive sampling placing value on their age, relationship status, educational background, and number of children. The researcher ensured variability of the sample so that the theory generated would take into consideration various experiences, and thus, a representative theory. A heterogeneous sample introduces to the theory more concepts or categories of data. Pseudonyms are assigned to each participant to help protect the participants' anonymity. Table 1 shows the demographic information of the participants.

\section{Table 1}

Demographics

\begin{tabular}{|c|c|c|c|c|c|}
\hline Participant & Age & Relationship Status & $\begin{array}{c}\text { Number of } \\
\text { Children }\end{array}$ & Occupation & $\begin{array}{c}\text { Educational } \\
\text { Attainment }\end{array}$ \\
\hline Jay & 29 & In a relationship & None & Call Center Agent & College Graduate \\
\hline Tin Tin & 30 & Cohabiting & 2 & Call Center Agent & College Level \\
\hline Andoy & 27 & Cohabiting & 1 & Sales Supervisor & College Graduate \\
\hline David & 28 & Cohabiting & None & Self-Employed & College Graduate \\
\hline Karl & 28 & Single & None & Barbecue Vendor & College Level \\
\hline Keith & 20 & Single & None & Student & College Level \\
\hline Fernando & 20 & Single & None & Student & College Level \\
\hline Jun & 42 & Married & 3 & Self-Employed & College Level \\
\hline Anthony & 24 & Single & 1 & Self-Employed & College Graduate \\
\hline Bok & 26 & Single & None & Engineer & College Graduate \\
\hline Tam & 49 & Married & 3 & Tricycle Driver & College Level \\
\hline Pete & 47 & Married & 2 & Factory Driver & College Level \\
\hline Elmo & 50 & Married & 2 & Rank and File & College Graduate \\
\hline Bogs & 16 & Single & None & Student & High School Level \\
\hline Fidel & 20 & Cohabiting & None & Employed & Vocational Degree \\
\hline Kevin & 28 & Cohabiting & 1 & Unemployed & Vocational Degree \\
\hline Red & 47 & Married & 5 & Unemployed & College Degree \\
\hline
\end{tabular}




\subsection{Procedure}

Data was gathered via interview and written reports of the participants. Treatment of data was done using the procedures outlined by Charmaz (2008), her procedures include a two-stage coding process using a constructivist lens. The first stage of the coding process was the initial coding followed by focused coding. Initial coding involves examining each line of data and defining or labelling the actions represented by it. The goal of initial coding is to simplify data and to identity recurring categories. During the initial coding process of this study which involved the first eight participants, 378 individual codes were identified. These codes included "concern for family", "family planning", "engage in traditional male activities", "attraction to females", and many more. The initial codes from the previous coding procedure then underwent focused coding. During this coding process the researcher identified the relationship among the initial codes. Focused coding enabled the researcher to identify recurring codes as well as superordinate codes - codes that subsume other codes. For example, codes such as "care for partner" and "concern for family" were merged to form "family oriented".

The new codes generated from this procedure where then applied to the existing data. The researcher then engaged in theoretical sampling to supplement the focused coding procedure, nine participants were added to the sample. Theoretical sampling was done to verify and explore the nature of the new codes. This sampling method ensures the validity of the results. For example, to explore the identity of men as fathers, more fathers were included in the study. Three superordinate codes or core categories were identified, as well as the codes that comprise them.

\section{Results}

The focus of this study was to develop a model that would closely look at how men view themselves as men and how their identities are formed. The study was able to identify two major identities that men have - their identity as a person and their identity as a father. Moreover, the study is able to point out that the identities of men do not just develop out of their own intuition and liking, but that their identities are shaped by specific experiences.

\subsection{Factors That Shape Men's Identity}

Social constructionism posits that no singular form of masculinity exists but that there are several masculinities (Pleck, Sonenstein, \& Ku, 1993). Masculinity is developed over time as a function of what men experience. In the study, the sample affirmed that indeed masculinity or their identities as men are shaped by the circumstances that they have been through. As a participant in the study said:

I can now say that I am a man. What make me a man are the experiences that I have been through. Everything that happened to me had an influence. If you interviewed me 10 years ago and I told you that I am a man, do not believe me.

Men in the study reported that the kind of men they are now is a product of their experiences. As they grew older, they began to accumulate more experiences and these had an impact on how they view themselves. Despite having gone through a multitude of experiences, several events stand out in the recollections of the men, such as their upbringing in their families, their experiences in school, the teachings of their religion, the social environment, and critical personal experiences.

Critical personal experiences will be discussed in this paper to highlight that a man's identity is a product of how one responds to the current context he is in. For example, Andoy stated that:

When my mother was dying and she was in the hospital my family was at a loss financially.

Every day there were numerous expenses. We sold our computer just to be able to have the money to spend for our mom. It was during this time where I told myself that I have to find a job. 
Before losing his mother, Andoy was a carefree person and only thought about himself. But when his mother got sick, he developed a concern for his family and he developed a sense of responsibility. This shift of concern from self to others was also demonstrated in the narration of Fidel. Fidel mentioned that he used to be involved with so many women; however, there was an instance when he caught his girlfriend cheating on him. Because of this, he realized how painful it was to be not taken seriously. After the said event, Fidel decided to be faithful to his partner and be serious in his romantic relationships.

Of all the events that have an impact on the identity of men, the experience of being a father seems to be the most influential. It is a general trend in the sample of this study that being a father entails a transformation in the identity of men, from being focused on themselves, to being focused on others and their family. Anthony, in his narration of his identity as a man mentioned that "Fatherhood changed me. Being a father defines my identity as a man". The centrality of fatherhood in the identity formation of men shows that male identity is formed as a result of contextual factors. In the study, how men think, behave, and feel change as they accumulated experiences. As their responsibility towards their family increased, their identities became more family oriented. As Tin Tin put it:

\section{What makes a "man” is his family.}

Due to this convergence of ideas about masculine identity, the researcher postulates that men have a progressive identity. This means that the identity of men in the study is continuously changing. Two major phases in the progression of masculine identity is identified. The first identity that men develop is their Identity as a Person (individual). This is then followed by their Identity as a Father. Men's identity as a person refers to how men view themselves before becoming fathers. This identity centers on how men define themselves, and what they value when they are still single. On the other hand, their identity as a father refers to how they view their gender identity after the experience of becoming a father.

\subsection{Identity as a Person}

Before becoming a father, men in the study report developing an identity that is mainly rooted on their personal wants and desires. Their identity as a person refers to how they think and define themselves during the period wherein they were single. As a person, men exhibit the following characteristics: They (1) are Attracted to females, (2) Value Courtship, (3) are Faithful, (4) Concerned with their Image, (5) Physically Strong, (6) Principled (7) enjoy Fun and Games, and (8) Desire to have a child.

Attracted to females - Men are attracted to females. This could be in the form of physical or sexual attraction, as well as simply wanting to be with females. It is common for men in the study to be attracted to several females at one time (even if they are in a relationship). However, it is important to note that this attraction does not always lead to intimacy and relationship formation. According to David, men are naturally attracted to females and this is a characteristic that separates men from women: "Men are physically attracted to women. That is what makes us different from women". Men in the study also describe that being with females is pleasurable. They explain that being with females feel good and that it is not at all times that their intention is to be in a relationship with a woman. Keith explains that being with women is for "accompaniment" and "fun". Due to this, participants seek out activities that would expose them to women. Jay stated:

\section{My friends would go out and drink, however drinking is against the teachings of my religion. So what I do is I just go out with them so I could meet girls.}

Courtship - Although men report to enjoy the presence of females and desire to physically be with them, they also report that they are interested to be to be a part of an intimate relationship. They take it to be their responsibility to initiate courtship. This means that it is their responsibility to woo women. It could be that men are attracted to several women at first but their physical attraction may lead them to like and pursue the woman. Further, men value courtship because this is a test of their masculinity. Karl describes his experience of doing his 
"best" for the woman he desires:

As much as possible, I made it a responsibility to be able to provide for my girlfriend. When we would go out I had to insist that we eat, even if she does not want to.

Faithful - Although men may not take women seriously at first, it seems that eventually they would do their best to make a woman like them and ultimately to keep a woman. When courtship is successful, men exhibit faithfulness in their relationships. Men report that they value being faithful to their partners. Being faithful means being contented with their current partner and resisting the urge to be with someone else. It also means fighting for the relationship. The capacity to be loyal is an indicator of masculinity and it has implications in the formation and preservation of one's future family. Renan explains that although he is still attracted to other females, he does his best to remain faithful to his current partner:

\section{It is natural to be attracted to several women. However, it is your responsibility to be loyal to your partner and take care of our relationship}

Concerned with their Image - Men in the study pay special attention to how they are perceived by others. Because of this concern they tend to behave according to the social prescriptions of their gender. Due to this concern men are motivated to be at their best in what they are doing. David admits that he feels the pressure to live up to the expectations of others. He states:

What tires me as a man is that I always have to impress other people and live up to their expectations. It seems that I have to be desirable to others always

Men in the study are affected by the feedbacks they receive from society regarding their gender identities. As a result, they do their best to keep their actions parallel to society's expectation. Indeed, gender identity is socially constructed (Kimmel \& Messner, 1989) and as a result, men in the sample show a deep concern for the image they project unto others.

Physical Strength - Aside from their concerns involving women, men in the study show a particular concern for their bodies. Men have a strong physical build. This enables them to engage in traditional masculine activities. This enables men to be physically dominant over other people. Participants also report to be exposed to activities that involve inflicting physical pain on others; this action is intended to establish their position in society as well as to assert their masculinity. Andoy shares an experience where physical strength mattered and where he was able to assert his masculinity:

When I was in the $2^{\text {nd }}$ grade I had a fight with a cousin who was bigger than me. He was no match so I was able to tell myself that I really am a man.

Further, physical strength is viewed as a hallmark of masculinity because it differentiates men from women. Participants report that being physically strong enables them to engage in activities that are labelled to be "for boys". In school and at home, they report that some tasks are assigned to because they are men.

Principled - Men in the study report that holding on to their personal values and beliefs is very important to them. According to the sample, a man stands by what he believes in. Karl clearly shows this in his statement:

It's not just about what you believe in, what matters are the principles you uphold.

Men in the study likened masculinity to a "core" characteristic of a person. They say that it is this inner characteristic that makes a man a man. Masculine identity is viewed to be entirely different from the overt behaviors of men. How men behave are merely manifestations of the principles they uphold and it is these principles that defines them. As what Karl mentioned in his view regarding homosexuals that they could be homosexuals on the "outside" but are "men on the inside". 
Being principled also means being able to push forward one's beliefs as long as one know he is right. A man understands, but when others clash with his personal values, he makes it a priority to argue for his position. Men in the study believe that part of what makes them masculine is their capacity to live up to the principles they have. They point out that being masculine is beyond the physical and social aspects but rather it is in the core beliefs and action of an individual.

Fun and Games - Before becoming a family man, men view having fun (enjoying) as a priority. This means that they are frequently taking part in games, hobbies, and other activities that are hedonistic. This hedonistic concern is common for men who are young and single. As stated by Tin Tin and David, before becoming fathers, their days were spent on enjoying themselves. They were living carefree lives and it seemed to them that there are no boundaries in the activities that they can do. Tin Tin was into "drugs, alcohol, women, and computer games" and David was into "partying, drinking, and going out".

Living a lifestyle that is based on having fun may be indicative of the priorities of men before they enter family life. Bogs, who was addicted to computer gaming stated:

I used to think that life was like a game. You had to play to be successful. You sacrifice your friends or just leave them behind. You just play with the people that surround you. Life is a game, you play so the game won't end.

This means that young men not yet have a clear sense of direction or responsibilities. Their engaging in these activities may be a mark of this kind of thinking. In summary, men in the study show that at an early part in their life, they are into living by the moment and basking in the pleasures different activities - games, travel, vices, etc.

Desire to have child - Despite the fact that men in the study are immersed in enjoying their lives by engaging in meaningless activities when they are younger, when they mature they report that having a child becomes a priority for them. Andoy even reports that he has set a timeline for himself on when he should have a child. He said that "by the age of 26 I should have a child".

It is also worth mentioning that men in the study show a desire to have a child and view marriage to be a part of the process of becoming a father. Men in the study who are currently in a relationship view having a child to be a higher level goal compared to being married. It could be that men in that study view marriage as a step towards fatherhood. Jay in his narration regarding his relationship stated:

\section{I plan to marry next year. I have a girlfriend now and we are planning about starting a family and having children.}

One participant in the study admits that he and his partner (they have been cohabiting for almost two years) have been trying to conceive. Unfortunately, they have been unsuccessful. His sentiment below show how much value he places on having a child:

\section{I am still doubtful about who has a problem - me or my partner. I can accept the fact that I would not become a father. But as a man, I desire to have a child.}

Becoming a father is very important for men. Men in the study view becoming a father as the topmost priority. They even equate becoming a father as the ultimate measure of being a man. True enough, when men become a father, the characteristics that define their masculinity changes. For example, their principles begin to focus around family and their interest in fun and games decreases. The characteristics enumerated and explained above are the defining characteristics of man's identity as a person - man who is single and whose primary concern is his own person/self. Through looking at the accounts of men in the study, the researcher observed that their identity changes once they become a father. It seems that from being focused on the self, men are now focused on others - especially his family. 


\subsection{Identity as a Father}

As a Father, men exhibit the following characteristics: They (1) Prioritize their Family, (2) Provide for their Family, (3) Protect their Family, and (4) Care for their Family. These characteristics are salient for men who have entered fatherhood. These are what define their identities as men and as fathers.

Prioritize their Family - Men in study put their family above themselves. When one becomes a parent and a family man, his main life goal is to look after his family no matter what. This defining characteristic of a father may be an extension of him being principled. As noted earlier, being principled means behaving according to one's beliefs and value; during this period in man's life it is their family which they hold most valuable and it is their belief that they are responsible for their family. According to Karl, he is willing to "give everything" for his family even of there would be nothing left for him.

Prioritizing their family also means leaving behind activities that would compete with the time and effort that a man could allot for his family. Being a Father entails a change in the lifestyle of men such that they now engage in activities focused on their family and are minimally involved in activities that would only benefit themselves. Tin Tin, in his narration mentioned that he is not anymore involved in drug related activities and even does his best to distance himself from peers who are still into it. Andoy reports being less involved in violence related activities and he strives to stay healthy for his family:

Now that I have a child I am not short tempered anymore. I think about my family and so I refrain from engaging in violence... I used to be so carefree, but now after work I spend time with my family. During Sundays we go to church. I had no priorities then, but now if I have money I immediately save it for my family... I strive to keep myself healthy because if I get sick my family will get affected.

These accounts illustrate the substantial effect that fatherhood has on men. As well as how much importance and value men place on their families. It may be true that when they were younger they were concerned about pleasing themselves, but men who are now fathers seek to be the best that they can be for their family. At this point in their lives the daily activities of men are built around their families.

Provider for their Family - Being the best father for their family means being productive in their respective jobs and being able to provide for the needs of his family. Providing for their family appears to be a primary role for fathers. Providing support for the child seems to part of what defines a man. Participants in the study report that they are willing to exert a greater personal effort to ensure that they would be able to meet the demands of their family. Men in the study mention that the effort that they give in their jobs are doubled when they have a family of their own, compared to when they were still single or living with their parents. This is illustrated by Jun in the following statement:

When I was still under the care of my parents I knew I could still rely on them. I can choose to give them a part of my salary or not. But now that I have obligations for my family, all I think about is them. I have to double my effort for them.

This shows the significance that men place in the capacity to provide for their family. It was common for participants to report that since becoming fathers working overtime was routine. They also mentioned that looking for income generating activities outside of their work is normal. Not one man in the sample reported to be passive towards his family. All of them perceived family income to be their responsibility. Overall, being a father means dedicating one's time and effort in his job for his family.

Protect their Family - As a father, it is not enough for men to be limited to providing for the needs of their family. Though important, they also view protecting their families to be a defining characteristic. Protecting the family from physical harm and pain is a primary responsibility for a man. This characteristic of men to be 
protectors may be a derivative of their being physically strong. When they were younger, men used their physical strength to assert their position in society. However, as fathers, their physical strength is not any more used to inflict harm on others; this is now directed towards the preservation of their family. Keith notes that:

Being the man in the family, you should protect them. You should find ways to ensure that they do not get harmed. You should not inflict pain the family, but instead protect them.

Care for their Family - Aside from providing and protecting their families, men admit that they play an active role in taking care of their families - especially in the upbringing of their children. Men in the study view their children to be the heart of their families.

One is a man when he takes responsibility for his family. When you are married, you should look after your children.

In this statement by Jay, it is clearly pointed out that being a man means being responsible to both partner and child. His emphasis on the importance of marriage may indicate that one should be a responsible husband and treat his partner accordingly. Also, his statement demonstrates the weight that men place on being active in the upbringing of his child. This concern for the child's development is also shared by Tin Tin in his realization:

\section{I thought it would be enough for me to provide for the milk of the child. Later on I realized that a man should also be emotionally involved with the child.}

By pointing out to the emotions of men, Tin Tin implies that men are not only physically and financially present to the child but are also emotionally involved with the children. It could be inferred from this statement that fathers are involved in the holistic development of the child. It is not only a mother's role to take care of the child, as mentioned by Tam, "A father is responsible, caring, and loving. They share parental responsibility and child rearing together with the mother".

Although men in the sample do not say that not having a child makes a man less masculine, they agree that when one becomes a father, how he treats the child becomes the measure of his masculinity. His identity as a man is hinged on how he looks after his child. The core characteristic of a father is his capacity to be there for his child.

\section{Discussion}

\subsection{General Discussion}

Men are shaped by the experiences that they have undergone. Their idea of who they are and what kind of men they are is continuously developed as they go by life's ebbs and crests. Their interaction with their immediate surroundings and events give life to their conceptions of their identity as men. Their parents, school, peers, religion, critical personal experiences, and fatherhood teach them about what it means to be a man.

Throughout men's lives, their identities undergo progressive changes. These changes in their identity are brought about by several factors. It could be observed that men's identity is shaped by external factors. From their experience they get to know what qualities they should uphold as men, as well as what characteristics they are to demonstrate. Based on the analysis of the reports of the participants in the study, the progression of their identities undergoes two major phases.

First, men define themselves according to characteristics that they value as individuals. This identity remains fairly stable until the instance (event) they become a father. Due to fatherhood, the identities of men are then modified. They now identify as men who dedicate their lives to their family, especially their child. From having a self-focused identity, men become family-focused, entailing a shift in what they prioritize and a change in their responsibilities. However, it is important to note that this does not mean they lose their identity as a 
person, this simply implies that their identity shifts in saliency of characteristics. In the diagram this is illustrated by the overlap of the two identities.

Because their circumstances changes across time, so does their values, beliefs, priorities, and behaviors. The number of influences and critical events that men undergo is limitless; it is only bounded by the length of their existence. However, in the study, common events were identified and thus a shared identity was outlined. Male identity is therefore a construct that is shaped several life events and experiences.

\subsection{Relationship of Grounded Theory to Existing Literature}

As stated by Kimmel and Messner (1989) how men view themselves is a learned construct. It is created throughout their interaction with their environment. The study was able to show that indeed the identities of men are constructed based on their life experiences. Further, the study was able to identify some factors that play a major role in the formation of male gender identity. For example, in the study it was shown that fatherhood greatly influences how men view themselves. Fatherhood caused the men in the study to shift their priorities. It changed the salient characteristics that men have. The emerging theory also adds to Wood's (2009) idea that gender is not stable by pointing out that men's gender identity is progressive. A progressive identity means that how men view themselves changes, and that this change follows a certain path. They start out as being self-centered and then move to be family-centered. Their experiences as a person are important as it is a prerequisite to their identity as a father.

The model in the study also shows resemblance existing theories in the field. For example, Bem (1981) stated that the social environment of children is gendered. This means that how the environment that surrounds children is designed to match with the birth sex of the child. In the accounts of some of the participants in the study it was seen that they were able to note how their experience in school has influenced their ideas of who they are. This could be because the educational setting varies in terms of how it treats boys and girls. Further, men in the study state that they have a concern for how they are perceived by others. This shows that men are experiencing social pressures that force them to conform to what others are expecting. The study was not just able to confirm the gendered environment assumption; the study was able to explicitly identify the factors that have an impact on the identity of men. One factor identified in the study is the role of parents in the formation of the identity of the participants.

Participants stated that their ideas about how to behave as men were learned from what they perceived from their parents. This is in line with the gender modelling theory proposed by Bussey and Bandura (2004). Participants were highly influenced by other people as indicated in the study. This may be because they view other people as models for their identity. Male identity may have been patterned after other men that participants interacted with. However, the study also pointed out that although men pattern their behaviors after other men, their behaviors and identity are not an exact replica of the model. Participants of the study state they use other people as a benchmark for their identities. This is illustrated by the participants' desire to be better in taking care of their children that their parents. Further, the study shows that men choose the models they attend to. For example, some participants opted to leave their peer group due to the negative influence this has on their identity. Modelling plays an important role in the construction of gender identity but this is largely a conscious process, as explained by some participants.

Participants in the study identified a shift in their responsibilities as they become a father. This may entail a shift in the role they follow as men. One view of gender states that gender is a role (West \& Zimmerman, 1987). In the study the acquisition of the role of father greatly contributed to how men see themselves. It could be inferred from this that the responsibilities associated with the role of being father hugely had an impact on the identities of men. This is also in line with the assertion of (Deaux \& Major, 1987) that the expression of gender varies as a function of situational demands. Because being a father entails different responsibilities, men began to change their behaviors and ultimately, their identities. It is also worth noting, that in the study the role of being 
a father encompasses other roles. For example, men view their role as a worker to be highly related to being a father. Men work hard to perform better as fathers.

The study was also able to highlight the impact that fatherhood has on men as well as how men behave as fathers. The core responsibility of fathers, as illustrated in the model is the upbringing of children. The engagement of father in the upbringing of their children is referred to as paternal involvement. According to Lamb, Pleck, Charnov, and Levine (1987), paternal involvement has three components: interaction, accessibility, and responsibility. The study elaborates this model by explicitly showing what men do as fathers. Specifically, the participants report that they have direct experience in taking care of their child. They also mention that their involvement with their children is beyond providing for their material needs. They are active in caring for their child and they view the welfare of their child to be their primary responsibility. Men view raising their children as a defining feature of their identity.

The accounts of men in the study also reflect the existence of Filipino masculinity. It does not only add to the existing literature on Filipino masculinity, it gives a new perspective on how Filipino masculinity should be viewed. The emergent theory show that the identity of men is not only context dependent (e.g. Aguiling-Dalisay et al., 2000) but that it also has a temporal dimension. Masculinity changes across time. Further, unlike the previous studies on Filipino masculinity, the study does not only describe the Filipino man, it also traces the formation of their identities.

Overall, the study is in line with some of the existing theories of gender identity development. The grounded theory is able to put into concrete terms the assumptions of these theories. The study also touches on aspects of masculinity that these theories have not covered. For example, findings of the study offer depth that social-cognitive theories are not able to cover.

The model derived from the accounts of the participants offers us a window into understanding how masculine gender identity is constructed. Through the lens of grounded theory the study is able to arrive at an emic explanation of masculine identity formation. Cabrera, Tamis-LeMonda, Bradley, Hofferth, and Lamb (2000) stated that no single definition of fatherhood and fathers' role exist. This means that a fathers' view of himself is shaped by social factors such as family, community, and history. Although the study only shows one view of masculinity, it reflects the malleable nature of male identity.

\subsection{Implication of the Study}

Implications for future research - The current study demonstrates that like other identities, male identity is formed over time and experience. Male identity is just one of the many identities under the gender spectrum and this study might have an implication on the development of other gender identities. For example, the study provides a starting point for researchers who are interested in identifying crucial variables that influence gender identity formation. The study also could provide a reference point for the study of the identity of females because both genders can experience becoming a parent. Future studies could look into the identity of men who come from backgrounds that are different from those in this study. Also, it would be interesting to investigate the identities of men who are in the twilight of their lives as the circumstances surrounding old age is different from young and middle adulthood. Moreover, since the participants were self-identified straight males, a study involving gays may bring about another perspective of male gender identity.

Implications for institutions that cater to men - All the institutions that surround men, from school to companies, should be aware of the role they play in the lives of men. If we want to see better men, then institutions that cater to their needs should be more sensitive. For example, in psychotherapy and counseling, psychologists should be sensitive to the issues that men are facing and treat them differently from other groups (e.g. women) because men have different life concerns and priorities. In school, teachers should be mindful of the concerns of boys and men because these may vary from one another. They should be open to their behaviors as men are still in the process of establishing their identities. Moreover, teachers should also be sensitive to what 
they say regarding boys and men, they should not promote generic ideas about what a man is. Companies could also contribute to the development of men by providing them services and benefits that are in line with their identities, such as paternal benefits, and activities that would strengthen the bond between father and family.

Implications for the general public - It is a common practice that gender is used interchangeably with biological sex. The emerging theory refutes this and it could be observed that men learn how to be men. The process outlined in this study allows us to pinpoint the influences and factors that play a huge role in the shaping of male identity. This knowledge does not only allow us to understand but also to intervene (if needed) in the formation of their identity. For example, since the study shows that men admit to the impact family upbringing has on their identity, families and parents should be more sensitive about how they treat boys and men in their family. If they want young boys to grow up to be successful men then they should demonstrate the characteristics that comprise a successful man. As seen in the study, men might start out to be carefree, but they eventually become focused and responsible. Men change and so should our views and actions towards them.

\subsection{Limitations of the study}

The study did not seek to generalize its findings to the general male population. It only aimed to understand in depth the circumstances of the men being studied. The results of the study only stand true for men who are similar to those being studied. Therefore, caution should be put to mind when applying the results of this study to their practice as researchers, psychologist, counselor, and the like. The findings of the study are not true for all men, but it gives us a glimpse into the spectrum of male gender identity.

\section{Conclusion}

The study aimed to create a model of male gender identity through the application of grounded theory advocated by Charmaz, (2008). The objective of the study was to develop a model that would be endemic and specific to the target group. The methodology enabled the researcher to identify two phases of male identity formation, as well as the variables that had an impact on these. Men in this study narrated that their identities are defined by the experiences that they have been through. They share that how they see themselves is a result of their circumstances. Two identities that men in the study have are that of a Person and of a Father.

As a person, men stated that their primary concern was enjoying their life, having fun, forming and maintaining meaningful relationships with women, and standing by what they believe in. They were also concerned about keeping up with society's expectations of them. This identity then loses its saliency when men become fathers. As a father, men in the study report that their families become the heart of their existence. They cite how they now act more responsibly for their families. Men in the study seek to be the best father to their children. They equate being a good father to being a good man. They indicate that the best measure of masculinity is how one performs as a father. Male identity is therefore malleable. It changes across time and experience. There may truly be numerous masculinities and there is no doubt that experience is the father of man.

Acknowledgement: This paper was supported by the Commission on Higher Education (CHED thesis grant, CMO No. 33 s. 2004).

\section{References}

Aguiling-Dalisay, G., Mendoza, R., Mirafelix, E., Yacat, J., Sto. Domingo, M., \& Bambico, F. (2000). Pagkalalake (Masculinity): Men in Control? Filipino male views on love, sex, and women. Quezon City, Philippines: Pambansang Samahan ng Sikolohiyang Pilipino (National Association of Filipino Psychology).

Aguiling-Dalisay, G., Nepomuceno-Van Heugten, M. L., \& Sto. Domingo, M. (1995). Ang pagkalalaki ayon sa 
mga lalaki: Pagaaral sa tatlong grupong cultural sa Pilipinas. Philippine Social Sciences Review, 52, $143-166$.

Bandura, A. (1986). Social foundations of thought and action: A social cognitive theory. Englewood Cliffs, NJ: Prentice-Hall

Bem, S. (1981). Gender schema theory: A cognitive account of sex typing. Psychological Review, 88, $354-364$. http://dx.doi.org/10.1037/0033-295X.88.4.354

Bussey, K., \& Bandura, A. (2004). Social cognitive theory of gender development. In A. Eagly, A. Beall, \& R. Sternberg (Eds.), The psychology of gender (pp. 92-119). NY: Guilford Press.

Cabrera, N. J., Tamis-LeMonda, C. S., Bradley, R. H., Hofferth, S., \& Lamb, M. E. (2000). Fatherhood in the twenty first century. Child development, 71, 127-236. http://dx.doi.org/10.1111/1467-8624.00126

Charmaz, K. (2008). Grounded theory. In J. A. Smith (Ed.), Qualitative psychology: A practical guide to Research Methods (2 ${ }^{\text {nd }}$ ed., pp. 81-110). Singapore: Sage Publications Ltd.

Deaux, K., \& Major, B. (1987). Putting gender into context: An interactive model of gender related behaviour. Psychological Review, 94, 369-389. http://dx.doi.org/10.1037/0033-295X.94.3.369

Donahue, E., Robins, R., Roberts, B., \& John, O. (1993). The divided self: Concurrent and longitudinal effects of psychological adjustment and social roles on self-concept differentiation. Journal of Personality and Social Psychology, 64, 834-846. http://dx.doi.org/10.1037/0022-3514.64.5.834

Frankel, L. (2004). An appeal for additional research about development of heterosexual male sexual identity. Journal of Psychology \& Human Sexuality, 16(4), 1-16. http://dx.doi.org/10.1300/J056v16n04_01

Hoffman, R. (2004). Conceptualizing heterosexual identity development: Issues and challenges. Journal of counselling \& development, 82, 375-380. http://dx.doi.org/10.1002/j.1556-6678.2004.tb00323.x

Jimenez, M. C. (1983). Masculinity or femininity concepts of Filipino man and woman. Proceedings of Development in Philippines Psychology, 19, 91-100.

Kimmel, M., \& Messner, M. (1989). Men's lives (8th ed.). Boston, Mass.: Allyn \& Bacon.

Lamb, M. E., Pleck, J. H., Charnov, E. L., \& Levine, J. A. (1987). A biosocial perspective on paternal behaviour and involvement. In J.B. Lancaster, J. Altman, A. Rossi, \& L. R. Sherrod (Eds.), Parenting across the lifespan: Biosocial perspectives (pp. 111-142). New York: Academic.

Pleck, J. H., Sonenstein, F. L., \& Ku, L. C. (1993). Masculinity Ideology and its Correlates. In S. Oskamp \& M. Costanzo (Eds.), Gender Issues in Social Psychology (pp. 85-110). Newbury Park, CA: Sage.

Rheingold, H., \& Cook, K. (1975). The content of boy's and girl's room as index of parents behavior. Child Development, 46, 459-463. http://dx.doi.org/10.2307/1128142

Rodriguez, L.-L. (1990). Patriarchy and women's subordination in the Philippines. Review of Women's Studies, 1, $15-25$.

Rubio, R. J., \& Green, R. -J. (2011). Filipino men's roles and their correlates: Development of the Filipino adherence to masculinity expectations scale. Culture, Society, \& Masculinities, 3, 77-102. http://dx.doi.org/10.3149/CSM.0302.77

West, C., \& Zimmerman, D. (1987). Doing gender. Gender \& Society, 1, 125-151. http://dx.doi.org/10.1177/0891243287001002002

Wood, J. (2009). Gendered lives ( $8^{\text {th }}$ ed.). Boston: Wadsworth. 
Quinain, K. T. 